\title{
Current Standings of the Proton Pump Inhibitor and Clopidogrel Co-Therapy: Review on an Evolving Field with the Eyes of the Gastroenterologist
}

\author{
Márk Juhász László Herszényi Zsolt Tulassay \\ 2nd Department of Medicine, Semmelweis University, Budapest, Hungary
}

\section{Key Words}

Proton pump inhibitors $\cdot$ Clopidogrel $\cdot$ Myocardial

infarction - Gastroprotection

\begin{abstract}
The negative effect of proton pump inhibitors (PPI) on the antiplatelet function of clopidogrel has only recently emerged on the horizon of cardiological interest. To date, one can only find 10 peer-reviewed papers on PubMed on this issue, although the increasing activity is unquestionable. Besides publications, conference reports and official web sites are therefore important sources of information. In this field, the first step was made by an experimental study proving the adverse effect of omeprazole on clopidogrel function. Consequently, retrospective studies reported a significant increase of major adverse cardiovascular events among patients taking the combination of omeprazole and clopidogrel. Based on the paucity of quality data and limitations of studies conducted on this interaction, some are still reluctant to confirm the pathogenic role of PPI and clopidogrel interaction in the development of reinfarctions. One step further ahead, admitting the risks related to the combination of these two drugs, the next question to be decided is whether we face a class effect, or thanks to the different
\end{abstract}

metabolic pathways there are indeed relevant differences among PPIs. There is a lot at stake, since the volume of patients taking the dual aspirin-clopidogrel antiplatelet therapy and thereby needing gastroprotection is immense, rendering a huge responsibility to the societies and committees who are making proposals on the selection of appropriate PPIs.

Copyright $\odot 2009$ S. Karger AG, Basel

\section{The Scope of the Problem}

In the recent guidelines of national and international cardiology societies, patients with acute coronary syndrome (ACS) and/or percutaneous coronary intervention (PCI) are recommended to be on dual antiplatelet therapy (APT), i.e. aspirin and clopidogrel [1]. The most feared danger of APT is gastrointestinal hemorrhage which is more common in patients taking APT than in those taking placebo. The risk of bleeding seems to be dose-dependent for aspirin. When APT was given concomitantly with proton pump inhibitors (PPI), the incidence of gastrointestinal bleedings decreased [2].

Considering the huge volume of patients taking APT along with PPIs, it has been a remarkable turn of the last

\section{KARGER}

Fax +4161306 1234 E-Mail karger@karger.ch www.karger.com
(C) 2009 S. Karger AG, Basel

0012-2823/10/0811-0010\$26.00/0

Accessible online at:

www.karger.com/dig
Dr. Márk Juhász

2nd Department of Medicine, Semmelweis University

Szentkiralyi u. 46

HU-1088 Budapest (Hungary)

Tel. +3620982 7872, Fax +36 1266 0816, E-Mail juhaszmarkdr@gmail.com 


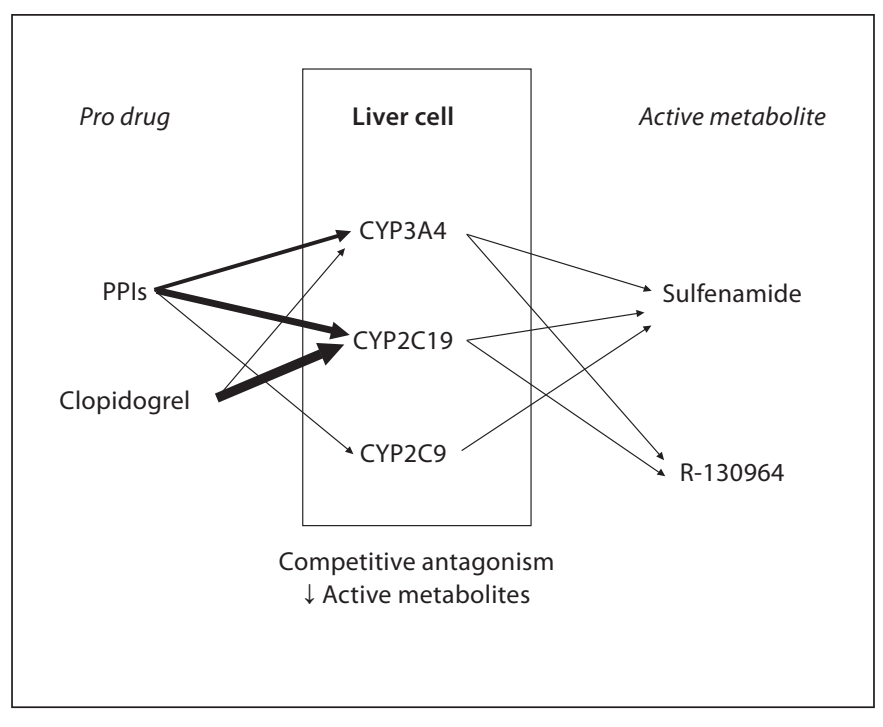

Fig. 1. Metabolic pathways of PPIs and clopidogrel in the liver. The thickness of the arrows leading from the prodrugs to the enzymes refers to the strength of the contribution of certain CYP450 enzymes to the conversion of prodrugs into active metabolites.

2 years that the incidence of myocardial infarction was three times higher when PPIs and clopidogrel were given together according to retrospective analyses [1]. This phenomenon is deemed to be due to the interaction between PPIs and clopidogrel as competing for the same CYP2C19 enzyme. This enzyme not only metabolizes PPIs, but also converts, as primary pathway, clopidogrel to its active metabolite, which is connected to the platelet P2Y12 ADP receptor through an inactivating disulfide bond. It is of prominent clinical significance that each PPI has unique metabolic pathways. The primary pathway is CYP2C19 for omeprazole, CYP3A4 for esomeprazole and lansoprazole, and $\mathrm{CYP} 2 \mathrm{C} 9$ for pantoprazole. Rabeprazole is metabolized via both CYP2C19 and CYP3A4 to equal extents (fig. 1).

The antiplatelet activity of clopidogrel is determined by the vasodilator-stimulated phosphoprotein (VASP) phosphorylation test-derived platelet reactivity index (PRI). Patients responding adequately to clopidogrel have a PRI under $50 \%$ [3]. The milestone of this issue is the prospective, randomized, placebo-controlled, doubleblind ex vivo study by Gilard et al. [4] where patients taking $75 \mathrm{mg}$ aspirin and $75 \mathrm{mg}$ clopidogrel after PCI received either $20 \mathrm{mg}$ omeprazole or placebo for 7 days. PRI was calculated on the 1st and the 7th day of omeprazole therapy. Both the omeprazole and placebo group present- ed a PRI of approximately $80 \%$ on the 1st day. However, on day 7, PRI was significantly higher $(p<0.0001)$ in the omeprazole group than on the placebo arm (51.4 and $39.8 \%$, respectively), referring to a significantly lower clopidogrel effect. The authors were modest enough to state that the relevance of their findings on the clinical practice is yet to be determined.

As aforementioned, apart from CYP2C19, CYP3A4 is also an enzyme for producing active metabolites out of PPIs and clopidogrel. The interaction between clopidogrel and atorvastatin has already been reported a couple of years ago $[5,6]$. An Austrian group that is yet to be cited on PPI-clopidogrel interaction later on evaluated the interaction between clopidogrel and amlodipine, a frequently prescribed calcium channel blocker, which interaction is also a consequence of the competitive antagonism for CYP3A4 [7].

\section{First Results on the PPI-Clopidogrel Interaction}

Both the American Heart Association (AHA) and the American College of Cardiology (ACC) recommend APT following coronary stenting [2]. The combination of clopidogrel and PPI diminishes the risk of gastrointestinal bleeding [8]. However, from the cardiologist's point of view, this combination may well be even dangerous, since recent studies suggested that PPIs can block the antiplatelet function of clopidogrel [9]. The AHA Scientific Sessions 2008 Symposium was held in the middle of November in New Orleans, where two studies with conflicting results were presented (table 1). In the first study, the major adverse cardiac events (MACE) of patients with coronary stents within their first year of clopidogrel therapy were evaluated [10]. Totally 14,383 patients from the Medco Integrated Database with a compliance of at least $80 \%$ were enrolled. The charts of patients taking clopidogrel $(n=9,862)$ were compared to those of patients taking clopidogrel plus PPIs $(n=4,521)$. In this latter group, there were significantly more MACEs recorded in the first year than in the solely clopidogrel group (adjusted OR 1.86, and 1.79 , respectively). One of the biases is that the clopidogrel-PPI combination group showed a higher cardiovascular risk profile that could partly explain why these patients were given PPIs for gastroprotection. Even the authors agree on some more limitations of their retrospective study: the database was blinded to the over-thecounter (OTC) medication intake (including aspirin and omeprazole), and there was a shortage of informa- 
Table 1. Summary of studies conducted on the interaction between clopidogrel and PPIs

\begin{tabular}{lcllll}
\hline Author & Ref. & PPI & $\begin{array}{l}\text { Number of patients on } \\
\text { PPI plus clopidogrel Rx }\end{array}$ & Study design & $\begin{array}{l}\text { Results } \\
\text { (OR for MACEs within 1 year) }\end{array}$ \\
\hline Gilard & 4 & OME & 70 & $\begin{array}{l}\text { prospective, } \\
\text { ex vivo }\end{array}$ & $\begin{array}{l}\text { on day } 7 \text { mean PRI significantly higher in } \\
\text { OME group }(\mathrm{p}<0.0001)\end{array}$ \\
\hline Aubert & 10 & n.d. & 4,521 & retrospective & $\begin{array}{l}\text { OR of 1.86 (CI 1.63-2.12) for plus-PPI group vs. } \\
\text { minus-PPI group }\end{array}$ \\
\hline Dunn & 11 & n.d. & 176 & retrospective & $\begin{array}{l}\text { OR of 1.633 (CI 1.015-2.627) for plus-PPI group vs. } \\
\text { minus-PPI group }\end{array}$ \\
\hline Juurlink & 12 & $\begin{array}{l}\text { PANTO; OME, } \\
\text { LANSO, RABE }\end{array}$ & 734 & retrospective & $\begin{array}{l}\text { OR of 1.02 (CI 0.7-1.47) for PANTO group } \\
\text { OR of 1.40 (CI 0.7-1.47) for OME-LANSO-RABE group }\end{array}$ \\
\hline
\end{tabular}

$\mathrm{PPI}=$ Proton pump inhibitor; $\mathrm{Rx}=$ therapy; $\mathrm{OR}=$ odds ratio; $\mathrm{MACE}=$ major adverse cardiovascular event; OME = omeprazole; $\mathrm{PRI}=$ platelet reactivity index; $\mathrm{CI}=95 \%$ confidence interval; $\mathrm{PANTO}=$ pantoprazole; $\mathrm{LANSO}=$ lansoprazole; $\mathrm{RABE}=$ rabeprazole.

a Adjusted OR for patients with a preceding MACE. ${ }^{\mathrm{b}}$ OR for death $<90$ days.

tion on the cardiovascular risk factors, such as family history, smoking, blood pressure, serum lipid levels. In the second study, which is in fact a retrospective subgroup analysis of a former large-scale study, the Clopidogrel for the Reduction of Events During Observation (CREDO) study, no harmful effect of the combination of PPI with clopidogrel could be identified [11]. The primary result of the CREDO study was the superiority of 1-year clopidogrel treatment after coronary stenting over the 1-month treatment. In the subgroup analysis, the mortality and the incidence of recent cardio- and cerebrovascular events were analyzed, with special respect to PPI consumption. No adverse effect of PPIclopidogrel combination could be detected. In either of the two studies, patients taking PPIs had already at baseline higher cardiovascular risk profiles. In the CREDO study, the adverse events among patients taking PPIs were not related to clopidogrel therapy. As the panel of the symposium agreed, neither of these two studies gave sufficient evidence to change the routine clinical practice.

The solution of these controversial results was expected from the Clopidogrel and the Optimization of Gastrointestinal Events (COGENT-1) study, where coronary patients taking aspirin-clopidogrel dual therapy were randomized to the PPI (20 mg omeprazole) arm, or to the placebo arm. The pill containing $75 \mathrm{mg}$ clopidogrel and $20 \mathrm{mg}$ omeprazole was coded CGT-2168, which was designed to be given on a once-a-day basis for 12 months. According to plans, 4,000 patients were to be enrolled into this double-blind, double-dummy third phase trial.
Unfortunately, on 22nd January this year, the sponsor of COGENT-1 suspended the trial. Hopefully, the authors will present at least an interim analysis of their data later on.

\section{Class Effect or Not?}

Currently, the light at the end of the tunnel is the study that is available online since 28th January this year, making larger and larger waves in the pharmaceutical industry [12]. Juurlink et al. [12] reviewed their material of an approximately 6-year-long period between April 1, 2002 and December 31, 2007. During this interval, the authors administered clopidogrel to 13,636 postinfarction patients. Finally, they enrolled 734 patients hospitalized for reinfarction, whereas the control group consisted of 2,057 persons. The start of PPI therapy was a key parameter of the study design; they categorized exposure to PPIs before the index date as current (within 30 days), previous (31-90 days) or remote (91-180 days). The incidence of MACE was determined on day 90 and 1 year after clopidogrel treatment. Reinfarction rate was found higher among current PPI exposure patients at both time-points, with OR being 1.27 (95\% CI 1.03-1.57). No increase in reinfarction rate was seen in the other two groups taking PPIs (previous and remote PPI intake), and among patients who did not receive clopidogrel therapy after myocardial infarction. Moreover, in patients taking anti-acid treatment not influencing CYP2C19, e.g. H2-blockers and pantoprazole, the rate of reinfarc- 
tion was also not increased - with OR for pantoprazole being 1.02 (95\% CI 0.70-1.47). On the contrary, patients treated with omeprazole, lansoprazole, or rabeprazole forming the 'other PPI' category presented an unequivocally higher risk for reinfarction, with an OR of $1.40(95 \%$ CI 1.1-1.77).

The authors keep on emphasizing the worldwide medical and economical aspects of their results. In 2007, clopidogrel came second on the selling list with USD 7.3 billion. Its two leading indications are myocardial infarctions and coronary stent implantation. The vast majority of clopidogrel patients take aspirin simultaneously, thereby multiplying the risk of a gastrointestinal hemorrhage. According to the joint recommendation of the AHA, the ACC and the American College of Gastroenterology (ACG), most of the patients with myocardial infarction, including all the above 60 patients take PPI in order to prevent gastrointestinal bleeding [2]. In Canada, the authors' residence, 12 million prescriptions were made for PPI in 2004. Taking the huge dimensions of PPIs and clopidogrel separately into account, the immense attention to the interaction between the two drugs is easy to understand. Should the adverse effect of the combination of clopidogrel with certain PPIs be confirmed prospectively in large patient cohorts as well, one cannot overestimate the importance of prescribing the appropriate PPI for gastroprotection. Juurlink et al. [12] prefer exclusively pantoprazole for the prevention of gastrointestinal hemorrhages in patients taking clopidogrel. One of their main supporting arguments could be what was highlighted previously in this review, and that is the fact that pantoprazole has a different primary pathway (CYP2C9) than clopidogrel (CYP2C19).

This study, however, has several limitations. The authors themselves admit that they had no reliable data on the cardiovascular risk factors (smoking, hypertension, serum lipid levels). Also, as a consequence of the retrospective setting, they had no clear vision on the OTC aspirin and PPI consumption. Moreover, case and control groups were not identical in every aspect. Miscoding and intermittent drug taking were further sources of mistakes. Despite all these remarks, Juurlink et al. [12] believe that these biases do not rule out the main message of their work. However, having thoroughly read their report, there are even more questions. The definition of the control group is not clear. The results of the 'other PPI' group are not detailed separately according to the sort of PPI given, so one cannot see how omeprazole, lansoprazole and rabeprazole performed individually. The authors do not mention why none of the patients received esomeprazole for gastroprotection. Even with this long list of critical comments to this study, the main merit cannot be denied, and that is raising motivation for other groups to confirm or deny these results by designing and executing somewhat more precise and, most importantly, prospective trials.

As mentioned above, for some unknown reason, Juurlink et al. [12] excluded esomeprazole. Fortunately, Siller-Matula et al. [13] filled this gap with their ex vivo work comparing the effects of pantoprazole and esomeprazole on clopidogrel activity. This Austrian group applied the same VASP method for defining PRI as Gilard et al. [4]. Similarly to the result of the retrospective Juurlink analysis, Siller-Matula et al. [13] found that pantoprazole does not influence the antiplatelet effect of clopidogrel. Furthermore, on the ex vivo level, esomeprazole did not decrease the function of clopidogrel either, probably because esomeprazole is metabolized mainly through other pathways than CYP2C19. In a cross-sectional observational study, Sibbing et al. [14] enrolled 1,000 consecutive patients under clopidogrel maintenance treatment scheduled for a control coronary angiography. The method of choice was multiple electrode platelet aggregometry for measuring adenosine diphosphate-induced platelet aggregation. Remarkably, hardly more than $25 \%$ of patients were on PPI prevention. Patients taking omeprazole as PPI produced a significantly higher platelet aggregation than patients off PPI. In line with the results of Siller-Matula et al. [13], in contrast to omeprazole, pantoprazole and esomeprazole did not influence platelet aggregation. However, unlike the Juurlink study with pantoprazole, a large-scale retrospective study on the relation between MACEs and esomeprazole is yet to be published.

\section{Current FDA and EMEA Standpoints}

Both the Food and Drug Administration (FDA) and the European Medicines Agency (EMEA) have promptly reacted to this newly emerged issue. The FDA early communication clearly states that currently available data can only provide momentary standpoints and our understanding must immediately be reconsidered as soon as quality data emerge [15].

'Until further information is available FDA recommends the following:

- Healthcare providers should continue to prescribe and patients should continue to take clopidogrel as directed, because clopidogrel has demonstrated benefits in 
preventing blood clots that could lead to a heart attack or stroke.

- Healthcare providers should re-evaluate the need for starting or continuing treatment with a PPI, including Prilosec OTC, in patients taking clopidogrel.

- Patients taking clopidogrel should consult with their healthcare provider if they are currently taking or considering taking a PPI, including Prilosec OTC.'

EMEA has also recently released a public statement on the possible interaction between clopidogrel and PPIs [16]:

'... the Agency's Committee for Medicinal Products for Human Use (CHMP) and its Pharmacovigilance Working Party (PhVWP) have recommended that the product information for all clopidogrel-containing medicines should be amended to discourage concomitant use of PPI and clopidogrel-containing medicines unless absolutely necessary.'

Unfortunately, this statement does not define the precise indication when the combination of a PPI with clopidogrel is 'absolutely necessary'. Unlike FDA, EMEA does not name any omeprazole-containing medicine, although omeprazole is the PPI that generated most of the conflicting results. To date, we have sufficient evidencebased data on the need and beneficial effects of PPIs preventing upper gastrointestinal bleedings in patients on APT. However, we only have two prospective ex vivo studies, and all the other data are coming from retrospective analyses that should 'discourage' us to prescribe PPIs for patients taking clopidogrel and aspirin. One of the key questions is whether this PPI-clopidogrel interaction phenomenon is undoubtedly a class effect, or whether there are indeed 'safe' PPIs. Consequently, prospective, randomized, double-blind multicenter trials of high statistical power with patients on dual aspirin-clopidogrel therapy taking PPIs for gastroprotection are highly warranted. Considering the worldwide dominance of both clopidogrel and PPIs, these types of quality studies are likely to be underway in the very near future.

\section{Recommendations}

In summary, the following recommendations for the PPI-clopidogrel interaction issue can be made:

(1) Patients requiring clopidogrel treatment, specially the ones taking dual aspirin-clopidogrel therapy and/or with a history of previous gastrointestinal hemorrhages, should be considered to be given PPI for gastroprotection.

(2) According to the current standings, this PPI should be pantoprazole.

(3) Esomeprazole may later prove to be an alternative.

(4) Since clopidogrel has several competitive antagonists, the risk of interactions affecting the clopidogrel function and thereby leading to MACEs rises if patients taking clopidogrel and PPI are treated with certain statins and calcium channel blockers additionally. The optimal approach to these patients would be to perform an ex vivo VASP test before the introduction of the required combined therapy in order to prevent myocardial (re-)infarction due to adverse drug interactions.

\section{References}

1 Trenk D: Proton pump inhibitors for prevention of bleeding episodes in cardiac patients with dual antiplatelet therapy - between Scylla and Charybdis? Int J Clin Pharmacol Ther 2009;47:1-10.

-2 Bhatt DL, Scheiman J, Abraham NS, Antman EM, Chan FK, Furberg CD, Johnson DA, Mahaffey KW, Quigley EM: ACCF/ ACG/AHA 2008 expert consensus document on reducing the gastrointestinal risks of antiplatelet therapy and NSAID use: a report of the American College of Cardiology Foundation Task Force on Clinical Expert Consensus Documents. Circulation 2008; 118:1894-1909.
-3 Barragan P, Bouvier JL, Roquebert PO, Macaluso G, Commeau P, Comet B, Lafont A, Camoin L, Walter U, Eigenthaler M: Resistance to thienopyridines: clinical detection of coronary stent thrombosis by monitoring of vasodilator-stimulated phosphoprotein phosphorylation. Catheter Cardiovasc Interv 2003;59:295-302.

4 Gilard M, Arnaud B, Cornily JC, Le Gal G, Lacut K, Le Calvez G, Mansourati J, Mottier D, Abgrall JF, Boschat J: Influence of omeprazole on the antiplatelet action of clopidogrel associated with aspirin: the randomized, double-blind OCLA (Omeprazole CLopidogrel Aspirin) study. J Am Coll Cardiol 2008; 51:256-260.
5 Clarke TA, Waskell LA: The metabolism of clopidogrel is catalyzed by human cytochrome P450 3A and is inhibited by atorvastatin. Drug Metab Dispos 2003;31:53-59.

-6 Lau WC, Waskell LA, Watkins PB, Neer CJ, Horowitz K, Hopp AS, Tait AR, Carville DG, Guyer KE, Bates ER: Atorvastatin reduces the ability of clopidogrel to inhibit platelet aggregation: a new drug-drug interaction. Circulation 2003;107:32-37.

7 Siller-Matula JM, Lang I, Christ G, Jilma B: Calcium-channel blockers reduce the antiplatelet effect of clopidogrel. J Am Coll Cardiol 2008;52:1557-1563. 
8 Ng FH, Lam KF, Wong SY, Chang CM, Lau YK, Yuen WC, Chu WM, Wong BC: Upper gastrointestinal bleeding in patients with aspirin and clopidogrel co-therapy. Digestion 2008;77:173-177.

9 Ho PM, Maddox TM, Wang L, Fihn SD, Jesse RL, Peterson ED, Rumsfeld JS: Risk of adverse outcomes associated with concomitant use of clopidogrel and proton pump inhibitors following acute coronary syndrome. JAMA 2009;301:937-944.

10 Aubert R, Epstein RS, Teagarden JR, Xia F, Yao J, Desta Z, Skaar T, Flockhart DA: Proton pump inhibitors effect on clopidogrel effectiveness: the Clopidogrel Medco Outcomes Study (abstract 3998). Circulation 2008;118:S815.
11 Dunn SP, Macaulay TE, Brennan DM, Campbell CL, Charnigo RJ, Smyth SS, Berger PB, Steinhubl SR, Topol EJ: Baseline proton pump inhibitor use is associated with increased cardiovascular events with and without the use of clopidogrel in the CREDO Trial (abstract 3999). Circulation 2008;118: S815.

12 Juurlink DN, Gomes T, Ko DT, Szmitko PE, Austin PC, Tu JV, Henry DA, Kopp A, Mamdani MM: A population-based study of the drug interaction between proton pump inhibitors and clopidogrel. CMAJ 2009 [Epub ahead of print].

13 Siller-Matula JM, Spiel AO, Lang IM, Kreiner G, Christ G, Jilma B: Effects of pantoprazole and esomeprazole on platelet inhibition by clopidogrel. Am Heart J 2009 157:148.e1e5.
4 Sibbing D, Morath T, Stegherr J, Braun S, Vogt W, Hadamitzky M, Schömig A, Kastrati A, von Beckerath $\mathrm{N}$ : Impact of proton pump inhibitors on the antiplatelet effects of clopidogrel. Thromb Haemost 2009;101: 714-719.

15 http://www.fda.gov/Drugs/DrugSafety/ PostmarketDrugSafetyInformationforPatientsandProviders/DrugSafetyInformationforHeathcareProfessionals/ucm079520. htm - Early Communication about an Ongoing Safety Review of clopidogrel bisulfate (marketed as Plavix).

16 http://www.emea.europa.eu - EMEA public statement on possible interaction between clopidogrel and proton pump inhibitors. London, 2009, EMEA/328956/2009. 